\title{
Further evidence for the theory that crossover interference in Drosophila melanogaster is dependent on genetic rather than physical distance between adjacent crossover points
}

\author{
Petter Portin \\ Laboratory of Genetics, Department of Biology, University of Turku, Turku, Finland \\ Email: petter.portin@utu.fi
}

Received 19 May 2012; revised 28 June 2012; accepted 10 July 2012

\begin{abstract}
Effect of heat shock on certain meiotic parameters in Drosophila melanogaster was studied in the $c v$ - $v$ - $f$ region of the $\mathrm{X}$ chromosome of females homozygous for mus309 mutation, deficient in DNA double-strand break repair, or being of wild type. The heat shock in the wild females caused that the frequencies of the single crossovers and all the map lengths decreased while the frequency of the double crossovers and crossover interference remained unchanged. In the mus309 mutants all parameters remained unchanged except that single crossovers in the $c v-v$ interval were less frequent, and that crossover interference diminished. Thus, heat shock seems have two separate effects; one being independent on the mus309 gene and affecting the occurrence of crossing over itself, and the other being dependent on the mus309 gene and affecting some precondition of crossing over. This precondition is probably the choice between two routes of the repair of double-strand DNA breaks known to be controlled by the mus309 gene. The results are in accordance with the genetic models of interference in which interference depends on genetic distance between the crossover points, but in contradiction with physical models where interference is dependent on physical distance between the crossover points.
\end{abstract}

Keywords: Chiasma; Chromosome; Map Length; Meiosis

\section{INTRODUCTION}

\subsection{General Introduction}

Meiotic crossing over, the exchange of genetic material between homologous chromosomes during the generation of gametes in animals and sexual spores in plants and fungi leads to recombination of genes and formation of chiasmata. A chiasma is a sufficient condition for the segregation of homologous chromosomes, which leads to the reduction of the chromosome number from diploid to haploid.

An important phenomenon, which has recently garnered much attention, associated with crossing over is crossover interference, i.e. the fact that multiple crossovers in each pair of homologous chromosomes are less frequent than would be expected on the basis of random coincidence of single crossovers [1-3]. The phenomenon of crossover interference is very likely responsible for the occurrence of so called obligate crossovers, and thus for the formation of obligate chiasmata.

The term "obligate crossover" refers to the fact that, in most species, it is rare to find chromosomes that do not undergo crossing over. For example, in Drosophila, there is usually one chiasma per chromosome arm. The feature of the obligate chiasma is biologically sensible because it ensures the disjunction of homologous chromosomes.

\subsection{Models of Crossover Interference and the Purpose of the Present Study}

In principle, there are two different categories of models of crossover interference. The first of these categories of models are called genetic models which assume that interference depends on the genetic (i.e. linkage map) distance, measured in Morgans, between adjacent crossovers [4]. To my knowledge, currently only one model, called the "counting model", falls into this category $[4,5]$.

The second category of models, called physical models, hypothesize that crossover interference is dependent on the physical distance (microns or base pairs) between the adjacent crossovers. In general, these models, which are many, suggest that some kind of physical signal travels along the bivalent and determines the distribution of crossovers.

Recently I presented evidence for the genetic models of crossover interference in Drosophila melanogaster [6]. 
The aim of the present study was to get further evidence for the theory that crossover interference is dependent on genetic rather than physical distances between adjacent crossover points. Crossing-over frequencies, crossover interference, recombination frequencies and map distances were compared in the $c v-v-f$ region of the $\mathrm{X}$ chromosome of D. melanogaster in females bearing either wild type 3rd chromosomes (control) or having the DNA double-strand break repair deficient $m u s 309^{D 2}$ / mus $309^{D 3}$ mutant constitution in the 3rd chromosomes (experiment), and given a heat shock of $24 \mathrm{hr}$ in $35^{\circ} \mathrm{C}$, or being without a heat shock.

It was observed that the heat shock in the wild control females caused that the frequencies of the single crossovers and all the map lengths decreased while the frequency of the double crossovers and crossover interference remained unchanged. In contrast to this, in the experimental mus309 mutant females all other meiotic parameters studied remained unchanged except that the frequency of the single crossovers in the $c v-v$ interval decreased, and that crossover interference diminished. Thus, it appears that the heat shock has two separate effects; one being independent on the mus309 gene and affecting the occurrence of crossing over itself, and the other being dependent on the mus309 gene and affecting some precondition of crossing over. It is suggested that this precondition of crossing over is the choice between two routes of the repair of double-strand DNA breaks known to be controlled by the mus309 gene. It should also be noted that the effect of the heat shock in the mutant females was generally speaking the opposition of its effect in the wild type females. These results are in accordance with the genetic models, particularly the counting number model, of interference in which interference depends on genetic distance between the adjacent crossover points, but the result is in contradiction with any physical model of interference where interference is dependent on physical distance between the adjacent crossover points.

\subsection{The mus309 Gene and Molecular Models of Crossing Over}

Molecular models of meiotic crossing over suggest that crossing over is initiated by the formation of meiosis-specific double-strand breaks (DSBs) of DNA, catalyzed eventually in all eukaryotes by the topoisomeraselike Spo11 protein, encoded in Drosophila by the meiW68 gene [7], in co-operation with other enzymes. The birth of DSBs is followed by formation of heteroduplex DNA and rejoining of the ends created in the breakage involving a single-end-invasion intermediate. Following this, a physical structure called the displacement loop will be formed. Subsequent DNA synthesis and second end capture form a structure known as the double Holliday junction (dHJ), which is then resolved to form either crossovers or non-crossovers [8,9].

Two alternative pathways for the repair of the DSBs are known: the synthesis-dependent strand annealing (SDSA) pathway and the double-strand-break repair (DSBR) pathway. The former pathway leads exclusively to non-crossover products and the latter to both crossover and non-crossover products [10,11].

In D. melanogaster, the mus309 gene located on the right arm of chromosome three (86F4) encodes, in a manner similar to its orthologues in other organisms, a RecQ helicase [12-15] and, accordingly, is involved in DSB repair $[10,11,16]$. In particular, it is known that the product of the mus309 gene is involved in the SDSA pathway of the repair of the DSBs $[17,18]$. More specifically, in the mus309 mutants the SDSA pathway is blocked, while the DSBR pathway remains functional [19]. Thus, the mus309 gene seems to control the choice made by the oocyte between the two alternative pathways of DSB repair. The same is also true for the $S g s 1$ gene, the mus309 orthologue of yeast [20]. Consequently, if in mus309 mutants more DSBs are repaired as crossovers by the DSBR pathway, a change in the crossover/ non-crossover ratio can be expected, since fewer noncrossovers are produced.

\section{MATERIAL AND METHODS}

\subsection{Experimental Procedures}

Crossing over frequency and interference in the $\mathrm{X}$ chromosome in the regions between the crossveinless $(c v, 1-$ 13.7), vermilion ( $v, 1$ - 33.0) and forked (f, 1 - 56.7) markers in four different experimental procedures were studied. In each procedure, six daily broods of progeny were derived after a certain treatment of virgin females before they were mated with males. The progeny was collected as daily broods in order to get the best yield of progeny flies. In the analysis of the results, however, the materials of the broods were pooled. The females were isolated and the treatment started not later than twelve hours after their hatching from the pupa. In the control crosses, $c v v f l+++$; +/+ females were crossed with $c v v$ $f / Y$ males, and in the experimental crosses, $c v v f l+++$; mus $309^{D 2} /$ mus $309^{D 3}$ females were crossed with $c v \vee f / Y$ males. The experimental females were derived from the following preliminary cross: $c v v f ; m u s 309^{D 3} / T M 6, T b$ females crossed with $+++/ Y$; mus $309^{D 2} / T M 6, T b$ males ( $\mathrm{Tb}$; Tubby 3 - 90.6) and identified on the basis of their non-Tubby phenotype. The treatments in both the control crosses and in the experimental crosses were as follows: The virgin females were either given a heat shock of 24 hours in $35^{\circ} \mathrm{C} \pm 0.5^{\circ} \mathrm{C}$ or they were kept in $25^{\circ} \mathrm{C} \pm 1^{\circ} \mathrm{C}$ for 24 hours. 
Both the mus309 alleles used carry mutational changes that could potentially impair or abolish at least the helicase function of the MUS309 protein. In mus $309^{D 2}$, there is a stop codon between the sequence motifs encoding the third and fourth helicase motif of the protein. $m u s 309^{D 3}$, for its part, has a glutamic acid to lysine substitution in the conserved helicase II motif, in addition to another amino acid substitution close to the $\mathrm{C}$ terminus [21]. It has been demonstrated that the genotype mus$309^{D 2} / m u s 309^{D 3}$ is semi-sterile (Janos Szabad, personal communication; see also [21-23]).

Because of the semi-sterility of the females, the mutant-female crosses were carried out in cultures in which three females were mated with 3 - 5 males, whereas the control crosses were single-female cultures. The same number (30) of crosses was made in both the control and the mutant-female series. After the initial mating, the parental flies were transferred without etherisation into fresh culture bottles every 24th hour for five consecutive days, and discarded after the sixth day of egg laying. The progeny, thus consisting of six daily broods in both the experimental and control procedure, were raised in $25^{\circ} \mathrm{C}$ on a standard Drosophila medium consisting of semolina, syrup, agar-agar and both dried and fresh yeast.

\subsection{Calculation of the Frequency of the True Single Crossovers}

Some of the observed single crossovers in the $c v-v$ and $v-f$ intervals actually result from meioses that have two exchanges, one in each interval. Assuming no chromatid interference, the three classes of double-exchange tetrads, 2-, 3- and 4-strand doubles, occur in a 1:2:1 ratio [24]. Therefore, the true frequency of single crossovers, i.e. the number of single crossovers that resulted from meioses with only one exchange in the $c v-v-f$ region, was calculated by subtracting the observed frequency of double crossovers from those of each of the single crossover classes.

\subsection{Measurement of Interference}

The coefficient of coincidence, $C$, was calculated according to the following formula of Stevens [25], which is a maximum likelihood equation

$$
\hat{c}=\frac{w n}{(w+x)(w+y)},
$$

where $w$ is the number of flies which were double crossovers, $x$ and $y$ are the numbers of flies which were single crossovers for $c v$ and $v$, and $v$ and $f$, respectively, and $n$ is the total number of flies.

The variance of $C$ was calculated according to the following formula, also given by Stevens [25]

$$
V(\hat{c})=\frac{c}{n}\left(\frac{1-c a-c b-c a b+2 c^{2} a b}{a b}\right),
$$

where $a$ and $b$ are the recombination frequencies of $c v$ and $v$, and $v$ and $f$, respectively. This is also a maximum likelihood equation.

\subsection{Statistical Methods}

In the calculations of the variance of the coefficient of coincidence, the formula of Stevens [25] given above was used. Otherwise, the variance of binomial frequencies, such as recombination frequencies, was calculated according to the usual formula: $s^{2}=p q / n$, where $n$ is the total number of flies, $p$ is the recombination frequency, and $q$ is $1-p$. The standard deviation (S.D.) of all the binomial frequencies the coefficient of coincidence included is the square root of their variances.

In the analysis of the significance of difference of the coefficients of coincidence and other binomial frequencies the two-tailed binomial t-test was employed.

\section{RESULTS}

The distribution of the progeny into different phenotypic classes in the control crosses is given in Table 1, and in the experimental crosses in Table 2.

The effect of the heat shock on the phenomenon of crossing over including crossover interference in the control cross females is given in Table 3. It appears that all the parameters studied except the frequency of double crossovers and the coefficient of coincidence changed due to the heat shock treatment. The frequencies of true single crossovers decreased in both intervals studied. The recombination frequencies, directly giving the genetic map distances between the markers involved, firstly of $c v$ and $v$ markers and secondly of $v$ and $f$ markers decreased, and so did—of course-also the map distance of the $c v$ and $f$ markers.

The respective figures derived from the experimental crosses are given in Table 4. The measurement of the parameters studied resulted in almost complete opposition of the parameters in the control crosses: All the parameters remained unaltered except that the frequency of true single crossovers in the $c v-v$ interval decreased and the coefficient of coincidence increased, i.e. crossover interference diminished. It should be noted that despite the fact that interference diminished, the frequency of double crossovers did not change at all. This must mean that the distribution of single crossovers changed becoming denser due to the heat shock treatment.

Comparison of the meiotic parameters between the genotypes studied in not-heat-shocked and in heat shocked females are given in Tables $\mathbf{5}$ and $\mathbf{6}$ respectively. As can be seen from the tables, all parameters except 
Table 1. Results of the control crosses. Distribution of progeny from the crosses in which $c v v f /+++;+/+$ females without or after a heat shock of $24 \mathrm{hr}$ in $35^{\circ} \mathrm{C}$ were crossed with $c v v f / Y$; +/+ males.

\begin{tabular}{cccccccccc}
\hline \multicolumn{10}{c}{ Number of progeny } \\
\hline Phenotype of the progeny & +++ & $c v v f$ & $c v++$ & $+v f$ & $c v v+$ & $++f$ & $c v+f$ & $+v+$ & Total number of flies \\
No heat shock & 4690 & 4311 & 1197 & 1243 & 1499 & 1577 & 147 & 179 & 14,843 \\
Heat shocked & 2428 & 2383 & 566 & 570 & 700 & 753 & 70 & 67 & 7537 \\
\hline
\end{tabular}

Table 2. Results of the experimental crosses. Distribution of progeny from the crosses in which $c v v f /+++; m u s 309^{D 2} / m u s 309^{D 3}$ females without or after a heat shock of $24 \mathrm{hr}$ in $35^{\circ} \mathrm{C}$ were crossed with $c v v f / Y$; $+/+$ males.

\begin{tabular}{ccccccccccc}
\hline \multicolumn{10}{c}{ Number of progeny } \\
\hline Phenotype of the progeny & +++ & $c v v f$ & $c v++$ & $+v f$ & $c v v+$ & $++f$ & $c v+f$ & $+v+$ & Total number of flies \\
No heat shock & 2545 & 2035 & 601 & 868 & 589 & 839 & 104 & 180 & 7761 \\
Heat shocked & 1661 & 1311 & 373 & 552 & 386 & 577 & 76 & 116 & 5054 \\
\hline
\end{tabular}

Table 3. Effect of heat shock on crossing over in females being of wild type regarding the mus309 locus. Parameters measured from the results of the crosses in which $c v v f /+++;+/+$ females without or after a heat shock of $24 \mathrm{hr}$ in $35^{\circ} \mathrm{C}$ were crossed with $c v v f / Y$; $+/+$ males.

\begin{tabular}{|c|c|c|c|c|c|}
\hline \multirow{2}{*}{$\begin{array}{l}\text { Parameter } \\
\text { Total number of flies }\end{array}$} & \multirow[b]{2}{*}{$\% \pm$ S.D. } & \multirow{2}{*}{$\begin{array}{c}\text { No heat shock } \\
14,843\end{array}$} & \multirow{2}{*}{$\begin{array}{c}\text { Heat shocked } \\
7532\end{array}$} & \multicolumn{2}{|c|}{ Significance of the difference } \\
\hline & & & & & \\
\hline $\begin{array}{l}\text { Frequency of true single crossovers in the } \\
c v-v \text { interval }\end{array}$ & $\% \pm$ S.D. & $14.24 \pm 0.29$ & $13.25 \pm 0.39$ & $\mathrm{t}=2.04$ & $P=0.04$ \\
\hline $\begin{array}{l}\text { Frequency of true single crossovers in the } \\
v-f \text { interval }\end{array}$ & $\% \pm$ S.D. & $18.53 \pm 0.32$ & $17.46 \pm 0.44$ & $\mathrm{t}=1.96$ & $P=0.05$ \\
\hline Frequency of double crossovers & $\% \pm$ S.D. & $2.20 \pm 0.12$ & $1.82 \pm 0.15$ & $\mathrm{t}=1.89$ & $\mathrm{P}=0.06$ \\
\hline $\begin{array}{l}\text { Recombination frequency of the } c v \text { and } v \\
\text { markers }\end{array}$ & $\% \pm$ S.D. & $18.64 \pm 0.32$ & $16.89 \pm 0.43$ & $\mathrm{t}=3.22$ & $\mathrm{P}=0.0013$ \\
\hline $\begin{array}{l}\text { Recombination frequency of the } v \text { and } f \\
\text { markers }\end{array}$ & $\% \pm$ S.D. & $22.92 \pm 0.34$ & $21.10 \pm 0.47$ & $\mathrm{t}=3.09$ & $\mathrm{P}=0.0020$ \\
\hline Map distance of the $c v$ and $f$ markers & $\mathrm{cM} \pm$ S.D. & $41.55 \pm 0.40$ & $37.99 \pm 0.56$ & $\mathrm{t}=5.13$ & $\mathrm{P}=0.0020$ \\
\hline Coefficient of coincidence & $\mathrm{C} \pm \mathrm{S} . \mathrm{D}$ & $0.5142 \pm 0.0253$ & $0.5101 \pm 0.0314$ & $\mathrm{t}=0.58$ & $P=0.56$ \\
\hline
\end{tabular}

Table 4. Effect of heat shock on crossing over in mus309 mutant females. Parameters measured from the results of the crosses in which $c v v f /+++$; mus $309^{D 2} / m u s 309^{D 3}$ females without or after a heat shock of $24 \mathrm{hr}$ in $35^{\circ} \mathrm{C}$ were crossed with $c v v f / Y$; $+/+$ males.

\begin{tabular}{|c|c|c|c|c|c|}
\hline \multirow{2}{*}{$\begin{array}{l}\text { Parameter } \\
\text { Total number of flies }\end{array}$} & \multirow[b]{2}{*}{$\% \pm$ S.D. } & \multirow{2}{*}{$\begin{array}{c}\text { No heat shock } \\
7761\end{array}$} & \multirow{2}{*}{$\begin{array}{c}\text { Heat shocked } \\
5054\end{array}$} & \multicolumn{2}{|c|}{ Significance of the difference } \\
\hline & & & & & \\
\hline $\begin{array}{l}\text { Frequency of true single crossovers in the } \\
c v-v \text { interval }\end{array}$ & $\% \pm$ S.D. & $15.27 \pm 0.41$ & $14.54 \pm 0.50$ & $\mathrm{t}=3.69$ & $\mathrm{P}=0.0002$ \\
\hline $\begin{array}{l}\text { Frequency of true single crossovers in the } \\
v-f \text { interval }\end{array}$ & $\% \pm$ S.D. & $14.74 \pm 0.40$ & $15.26 \pm 0.51$ & $\mathrm{t}=1.40$ & $\mathrm{P}=0.16$ \\
\hline Frequency of double crossovers & $\% \pm$ S.D. & $3.66 \pm 0.21$ & $3.80 \pm 0.27$ & $\mathrm{t}=0.41$ & $\mathrm{P}=0.68$ \\
\hline $\begin{array}{l}\text { Recombination frequency of the } c v \text { and } v \\
\text { markers }\end{array}$ & $\% \pm$ S.D. & $22.59 \pm 0.47$ & $22.14 \pm 0.58$ & $t=0.60$ & $\mathrm{P}=0.55$ \\
\hline $\begin{array}{l}\text { Recombination frequency of the } v \text { and } f \\
\text { markers }\end{array}$ & $\% \pm$ S.D. & $22.06 \pm 0.47$ & $22.85 \pm 0.59$ & $\mathrm{t}=1.05$ & $\mathrm{P}=0.29$ \\
\hline Map distance of the $c v$ and $f$ markers & $\mathrm{cM} \pm$ S.D. & $44.65 \pm 0.56$ & $44.99 \pm 0.49$ & $\mathrm{t}=0.38$ & $\mathrm{P}=0.70$ \\
\hline Coefficient of coincidence & $\mathrm{C} \pm \mathrm{S} . \mathrm{D}$ & $0.7344 \pm 0.0318$ & $0.7508 \pm 0.0447$ & $t=2.07$ & $\mathrm{P}=0.039$ \\
\hline
\end{tabular}


Table 5. Effect of the mus309 genotype on crossing over in females not given a heat shock. Comparison of parameters measured from the results of the crosses in which $c v v f /+++;+/+$ (control) and $c v v f /+++$; mus $309^{D 2} /{\text { mus } 309^{D 3}}_{\text {(experimental) females not }}$ given a heat shock were crossed with $c v v f / Y$; $+/+$ males.

\begin{tabular}{|c|c|c|c|c|c|}
\hline \multirow{2}{*}{$\begin{array}{l}\text { Parameter } \\
\text { Total number of flies }\end{array}$} & \multirow[b]{2}{*}{$\% \pm$ S.D. } & \multirow{2}{*}{$\begin{array}{c}\text { Control } \\
14,843\end{array}$} & \multirow{2}{*}{$\begin{array}{c}\text { Experiment } \\
7761\end{array}$} & \multicolumn{2}{|c|}{ Significance of the difference } \\
\hline & & & & & \\
\hline $\begin{array}{l}\text { Frequency of true single crossovers in the } \\
c v-v \text { interval }\end{array}$ & $\% \pm$ S.D. & $15.27 \pm 0.41$ & $14.54 \pm 0.50$ & $\mathrm{t}=2.06$ & $\mathrm{P}=0.0394$ \\
\hline $\begin{array}{l}\text { Frequency of true single crossovers in the } \\
v-f \text { interval }\end{array}$ & $\% \pm$ S.D. & $14.74 \pm 0.40$ & $15.26 \pm 0.51$ & $t=7.10$ & $\mathrm{P}<0.0001$ \\
\hline Frequency of double crossovers & $\% \pm$ S.D. & $3.66 \pm 0.21$ & $3.80 \pm 0.27$ & $\mathrm{t}=6.34$ & $\mathrm{P}<0.0001$ \\
\hline $\begin{array}{l}\text { Recombination frequency of the } c v \text { and } v \\
\text { markers }\end{array}$ & $\% \pm$ S.D. & $22.59 \pm 0.47$ & $22.14 \pm 0.58$ & $t=6.98$ & $\mathrm{P}<0.0001$ \\
\hline $\begin{array}{l}\text { Recombination frequency of the } v \text { and } f \\
\text { markers }\end{array}$ & $\% \pm$ S.D. & $22.06 \pm 0.47$ & $22.85 \pm 0.59$ & $\mathrm{t}=1.45$ & $\mathrm{P}=0.1471$ \\
\hline Map distance of the $c v$ and $f$ markers & $\mathrm{cM} \pm \mathrm{S} . \mathrm{D}$ & $44.65 \pm 0.56$ & $44.99 \pm 0.49$ & $\mathrm{t}=4.43$ & $\mathrm{P}<0.0001$ \\
\hline Coefficient of coincidence & $\mathrm{C} \pm \mathrm{S} . \mathrm{D}$ & $0.7344 \pm 0.0318$ & $0.7508 \pm 0.0447$ & $\mathrm{t}=31.78$ & $\mathrm{P}<0.0001$ \\
\hline
\end{tabular}

Table 6. Effect of the mus309 genotype on crossing over in heat shocked females. Comparison of parameters measured from the results of the crosses in which $c v v f /+++;+/+\left(\right.$ control) and $c v v f /+++$; mus $309^{D 2} /$ mus $309^{D 3}$ (experimental) females which had received a heat shock of $35^{\circ} \mathrm{C}, 24$ h were crossed with $c v v f / Y$; $+/+$ males.

\begin{tabular}{|c|c|c|c|c|c|}
\hline \multirow{2}{*}{$\begin{array}{l}\text { Parameter } \\
\text { Total number of flies }\end{array}$} & \multirow[b]{2}{*}{$\% \pm$ S.D. } & \multirow{2}{*}{$\begin{array}{c}\text { Control } \\
7532\end{array}$} & \multirow{2}{*}{$\begin{array}{c}\text { Experiment } \\
5054\end{array}$} & \multicolumn{2}{|c|}{ Significance of the difference } \\
\hline & & & & & \\
\hline $\begin{array}{l}\text { Frequency of true single crossovers in the } \\
c v-v \text { interval }\end{array}$ & $\% \pm$ S.D. & $13.25 \pm 0.39$ & $14.54 \pm 0.50$ & $t=2.06$ & $P=0.0394$ \\
\hline $\begin{array}{l}\text { Frequency of true single crossovers in the } \\
v-f \text { interval }\end{array}$ & $\% \pm$ S.D. & $17.46 \pm 0.44$ & $15.26 \pm 0.51$ & $\mathrm{t}=3.26$ & $\mathrm{P}=0.0011$ \\
\hline Frequency of double crossovers & $\% \pm$ S.D. & $1.82 \pm 0.15$ & $3.80 \pm 0.27$ & $t=6.13$ & $\mathrm{P}<0.0001$ \\
\hline $\begin{array}{l}\text { Recombination frequency of the } c v \text { and } v \\
\text { markers }\end{array}$ & $\% \pm$ S.D. & $16.89 \pm 0.43$ & $22.14 \pm 0.58$ & $\mathrm{t}=7.37$ & $\mathrm{P}<0.0001$ \\
\hline $\begin{array}{l}\text { Recombination frequency of the } v \text { and } f \\
\text { markers }\end{array}$ & $\% \pm$ S.D. & $21.10 \pm 0.47$ & $22.85 \pm 0.59$ & $\mathrm{t}=2.33$ & $P=0.0198$ \\
\hline Map distance of the $c v$ and $f$ markers & $\mathrm{cM} \pm$ S.D. & $37.99 \pm 0.56$ & $44.99 \pm 0.49$ & $\mathrm{t}=7.84$ & $\mathrm{P}<0.0001$ \\
\hline Coefficient of coincidence & $\mathrm{C} \pm \mathrm{S} . \mathrm{D}$ & $0.5101 \pm 0.0314$ & $0.7508 \pm 0.0447$ & $t=27.08$ & $\mathrm{P}<0.0001$ \\
\hline
\end{tabular}

the frequency of recombination of $v$ and $f$ markers in the not-heat-shocked females were different in both sets of data. It should specifically be observed that in both series the frequency of double crossovers and the coefficient of coincidence were higher in the mus309 mutant females than in the wild type females. These data indicate that in both series the density of crossovers increased due to the effect of the mus309 mutation.

\section{DISCUSSION}

\subsection{The mus309 Gene Controls the Choice Made by the Oocyte of the Route of Double Holliday Junction Repair}

The first six broods after the initiation of egg laying of virgin females, i.e. the broods constituting the material of this study represent oocytes which, for the most part at least, were in the prophase stage of meiosis during the heat shock treatment, and had mainly passed the stage of DNA replication during the premeiotic interphase [26-29]. DSB formation occurs only during the earlier stages of meiotic prophase and initiates at a specific time after premeiotic DNA replication [29]. Crossing over in D. melanogaster for its part is known to occur during the pachytene stage of the meiotic prophase [29,30], and the progenies in the 3rd brood represent this stage of meiosis [28].

It is convincingly established that those meiotic mutants of D. melanogaster affecting crossing over which also affect interference involve preconditions of crossing over, whereas those mutants that affect crossing over without affecting interference involve the crossing over event itself [31]. Consequently, the genes involved are called precondition genes and exchange genes, respectively.

This was theoretically shown by Sandler et al. [32] as follows: Let $a$ be the probability of the fulfillment of 
preconditions of crossing over in one region and only in that region in a three-point crossing-over experiment. Let $b$ be the probability of fulfillment of the same in another region and only in that region. Let $d$ be the probability of the fulfillment of the preconditions in both regions at the same time, and $x$ the probability of exchange, given the preconditions. From this it follows that the coefficient of coincidence, $C$, is

$$
C=\frac{\mathrm{d} x^{2}}{x(a+d) x(b+d)}=\frac{d}{(a+d)(b+d)}
$$

Since $C$ is independent of $x$, if a mutant that acts on crossing over also affects interference, it must influence the preconditions of crossing over. If, however, interference remains unaltered, the target of the effect is the exchange itself.

What in this respect is true for meiotic mutants is, of course, also true for other factors that affect crossing over, such as the heat shock treatment in the present study.

Heat shock in the control females affected the crossing over frequencies but interference remained unaltered (Table 3). Thus, taking the foregoing into account, it can without doubt be concluded that heat shock in the control females affected the event of crossing over itself.

In contrast to this, heat shock in the experimental females affected both the crossing over frequencies and interference (Table 4). Thus, heat shock in the presence of the mus 309 mutation affected some precondition of crossing over, and therefore mus309 belongs to the class of mutations that Baker and Carpenter [33] referred to as the "precondition mutants", meaning that they act prior to the time when crossovers are actually generated. This conclusion is strongly supported by the fact that interference decreased in the experimental mus309 mutant females as compared to the control females in both the non-heat-shock-treated and heat shocked females (Tables 5 and 6 ).

Thus, it appears that the heat shock has two separate effects; one being independent on the mus309 gene and affecting the occurrence of crossing over itself, and the other being dependent on the mus309 gene and affecting some precondition of crossing over.

As indicated in the introduction, the precondition of crossing over, which the mus 309 gene product affects, is the repair of DSBs - a necessary condition for crossing over. In particular, it is known that the MUS309 protein is involved in the SDSA pathway of the repair of the DSBs. Specifically, it is also known that in the mus309 mutants the SDSA pathway is blocked, while the DSBR pathway remains functional [19].

As also indicated in the introduction, of these pathways the SDSA pathway leads exclusively to non-crossover end products of the repairing process while the DSBR pathway leads to both non-crossover and crossover end products. Therefore, in the mus309 mutant females more DSBs are expected to be repaired as crossovers than in the wild type females. In other words, map lengths should be increased in the mus309 mutants as compared to the wild type females. This is precisely what was observed in the present study (Tables $\mathbf{5}$ and 6). Moreover, it should also be noted that, as indicated in the results, the data show that in both the non-heat-shock-treated and the heat shocked females the density of crossovers increased due to the effect of the mus309 mutation. The same result was obtained in the mus309 mutant females where the distribution of single crossovers became denser due to the effect of the heat shock. These two results show that in the mus309 mutant females more DSBs than in the wild type females are repaired as crossovers instead of non-crossovers.

Consequently, it is suggested that actually the precondition of crossing over which the mus309 gene affects seems to be the choice between the two routes of the DSB, or more precisely double Holliday junction, repair.

\subsection{Testing the Models of Crossover Interference}

This part of the discussion is mutatis mutandis similar with the respective discussion of an analogous series of experiments conducted by the present author where the effect of temperature on crossing over and crossover interference in mus 309 mutants of D. melanogaster was investigated [6]. The results of these two studies reciprocally support each others.

As mentioned in the introduction, models of crossover interference can, in principle, be divided into two different categories. The first category of models, called genetic models [4], assumes that interference is dependent on genetic (i.e. linkage map) distance (Morgans) between adjacent crossovers. To my knowledge, currently only one model, called the "counting model", [4,5] falls into this category.

The central feature of the counting model is that recombinational intermediates $(C$ 's) have two fates-they can be resolved with crossing over $(C x)$ or without $(C o)$. The $C$ 's are distributed at random with respect to each other, and interference results from constraints on the resolution of $C$ 's. The basic constraint is that each pair of neighboring $C x$ 's must have a certain number, $m$, of $C o$ 's between them, as if the meiocyte was able to "count" recombination events.

The second category of models, which may be called physical models, hypothesizes that crossover interference is dependent on physical distance (microns or base pairs) between the adjacent crossovers. In general, these models suggest that some kind of physical signal travels 
along the bivalent and determines the distribution of crossovers. One of the models belonging to this category, the reaction-diffusion model [34], is quantitative while the other models are qualitative.

According to the reaction-diffusion model, a "random walking" precursor becomes immobilized and matures into a crossover point. The interference is caused by a pair-annihilation of the random walkers, called the A particles, due to their collision together, or by annihilation of a random walker due to its collision with an immobilized point. This model has two parameters-the initial density of the random walkers, $\alpha$, and the rate, $h$, of their processing into crossover points. It is logical to conclude that interference decreases if the $\alpha$ value increases and/or $h$ decreases [34].

It is also quite logical to assume that if the mus309 mutations affect the balance by which the double Holliday junctions will be resolved as crossovers instead of non-crossovers the $m$ value of the counting model should decrease, and consequently interference should diminish, in the mus309 mutants. The results of the present study are consistent with this idea. It is, therefore, very probable that the mus309 mutation affects the Drosophila counting number, thus being the first mutation of this kind identified. Consequently, the results of the present study support the view that crossover interference in Drosophila is tightly tied to genetic distance.

In contrast, however, the results of the present study are not compatible with the reaction-diffusion model. According to this model, interference depends on two factors only, viz. the initial density of crossover precursors, i.e. DSBs, and the rate of their processing into crossovers. Therefore, it is hard to conceive, in terms of the reaction-diffusion model, how the number of crossovers, i.e. the map distances, would change due to the effect of temperature but their distances, i.e. interference, would not, as the initial density of DSBs does not change. This seems, however, to be the case in the results of the control crosses of the present study. Namely, because the coefficient of coincidence, $C$, did not change due to the heat shock treatment, it can be concluded that the initial density of the DSBs, i.e. the $\alpha$ value did not increase. Therefore, it cannot be assumed that the $\alpha$ value in the experimental crosses would change either.

Thus, if the reaction-diffusion model is correct, $h$ in the experimental crosses should decrease due to the heat shock treatment. This means that the coefficient of coincidence, $C$, should decrease. In fact, however, $C$ increased.

The results are also in contradiction with any model of crossover interference based on physical distance on the following grounds: The map distances in the experimental and control females are different, and react differently to heat shock, the map distances in the experimental crosses being not heat shock sensitive while the distances in the control crosses are heat shock sensitive. However, the crossover interference is independent of the heat shock in the control crosses, while in the experimental crosses interference is dependent on the heat shock. As explained above, this observation supports the models of interference based on genetic distance. On the other hand, the results are in contradiction with the models based on physical distance. In fact, if interference was dependent on physical distance, how could it change due to heat shock when both the genetic map distances and, naturally, the physical distances remain unchanged?

\section{ACKNOWLEDGEMENTS}

Thanks are given to Professor Janos Szabad (Szeged, Hungary) for introducing me to the mus309 gene, and the generous donation of the mutant stocks which, however, are also available from different stock centers. Skilful technical assistance by Mirja Rantanen, M.Sc. is gratefully acknowledged.

\section{REFERENCES}

[1] Sturtevant, A.H. (1915) The behavior of the chromosomes as studied through linkage. Zeitschrift für Inductive Abstammungs und Vererbungslehre, 13, 234-287.

[2] Muller, H.J. (1916) The mechanism of crossing over. American Naturalist, 50, 193-221. doi:10.1086/279534

[3] Hillers, K.J. (2004) Crossover interference. Current Biology, 14, R1036-R1037. doi:10.1016/j.cub.2004.11.038

[4] Foss, E., Lande, R., Stahl, F.W. and Steinberg, C.M. (1993) Chiasma interference as a function of genetic Edistance. Genetics, 133, 681-691.

[5] Mortimer, R.K. and Fogel, S. (1974) Genetical interference and gene conversion. In: Grell, R.F., Ed., Mechanims in Recombination, Plenum Press, New York, 263-275. doi:10.1007/978-1-4684-2133-0_23

[6] Portin, P. (2011) Effect of temperature on crossing over in the mus309 mutant, deficient in DNA double-strand break repair, of Drosophila melanogaster suggests a mechanism for crossover interference. Open Journal of Genetics, 1, 38-47. doi:10.4236/ojgen.2011.13008

[7] McKim, K.S. and Hayashi-Hagihara, A. (1998) mei-W68 in Drosophila melanogaster encodes a Spo11 homolog: Evidence that the mechanism for initiating meiotic recombination is conserved. Genes and Development, 12, 2932-2942. doi:10.1101/gad.12.18.2932

[8] Olsen-Krogh, B. and Symington, L.S. (2004) Recombination proteins in yeast. Annual Reviews of Genetics, 38, 233-271. doi:10.1146/annurev.genet.38.072902.091500

[9] Lorenz, A. and Whitby, M.C. (2006) Crossover promotion and prevention. Biochemical Society Transactions, 34, 537-541. doi:10.1042/BST0340537

[10] Heyer, W.-D., Ehmsen, K.T. and Solinger, J.A. (2003) Holliday junctions in eukaryotic nucleus: Resolution in sight? Trends in Biochemical Sciences, 28, 548-557. 
doi:10.1016/j.tibs.2003.08.011

[11] Heyer, W.-D. (2004) Recombination: Holliday junction resolution and crossover formation. Current Biology, 14, R56-R58. doi:10.1016/j.cub.2003.12.043

[12] Ellis, N.A., Groden, J., Ye, T.-Z., Staughen, J., Lennon, D.J., Ciocci, S., Proytcheva, M. and German, J. (1995) The Bloom's syndrome gene-product is homologous to RecQ helicases. Cell, 83, 655-666. doi:10.1016/0092-8674(95)90105-1

[13] Karow, J.K., Chakraverty, R.K. and Hickson, J.D. (1997) The Bloom's syndrome gene product is a 3'-5' DNA helicase. Journal of Biological Chemistry, 272, 3061130614. doi:10.1074/jbc.272.49.30611

[14] Mohaghegh, P., Karow, J.K., Brosh Jr., R.M., Bohr, V.A. and Hickson, I.D. (2001) The Bloom's and Werner's syndrome proteins are DNA structure-specific homologues. Nucleic Acids Research, 29, 2843-2849. doi:10.1093/nar/29.13.2843

[15] Wu, L., Davies, S.L., Levitt, N.C. and Hickson, I.D. (2001) Potential role for the BLM helicase in recombinational repair via a conserved interaction with RAD51. Journal of Biological Chemistry, 276, 19375-19381. doi:10.1074/jbc.M009471200

[16] Brabant, A.J. van Stan, R. and Ellis, N.A. (2000) DNA helicases, genome instability, and human genetic disease. Annual Reviews of Genomics and Human Genetics, 1, 409-459. doi:10.1146/annurev.genom.1.1.409

[17] Adams, M.D., McVey, M. and Sekelsky, J.J. (2003) Drosophila BLM in double-strand break repair by synthesis-dependent strand annealing. Science, 299, 265-267. doi:10.1126/science.1077198

[18] Laurencon, A., Orme, C.M., Peters, H.K., Boulton, C.L., Vladar, E.K., Langley, S.A., Bakis, E.P., Harris, D.T., Harris, N.J., Wayson, S.M., Hawley, R.S. and Burtis, K.C. (2004) A large-scale screen for mutagen sensitive loci in Drosophila. Genetics, 167, 217-231. doi:10.1534/genetics.167.1.217

[19] Portin, P. (2005) mus309 mutation, defective in DNA double-strand break repair, affects intergenic but not intragenic meiotic recombination in Drosophila melanogaster. Genetical Research, 86, 185-191. doi:10.1017/S0016672305007883

[20] Rockmill, B., Fung, J.C., Branda, S.S. and Roeder, G.S. (2003) The Sgs1 helicase regulates chromosome synapsis and meiotic crossing over. Current Biology, 13, 19541962. doi:10.1016/j.cub.2003.10.059

[21] Kusano, K., Johnson-Schlitz, D.M. and Engels, W.R. (2001) Sterility of Drosophila with mutations in the Bloom syndrome gene-Complementation by Ku70. Sci- ence, 291, 2600-2602. doi:10.1126/science.291.5513.2600

[22] Boyd, J.B., Golino, M.D., Shaw, K.E.S., Osgood, C.J. and Green, M.M. (1981) Third-chromosome mutagensensitive mutants of Drosophila melanogaster. Genetics, 97, 607-623.

[23] Beal, E.L. and Rio, D.C. (1996) Drosophila IRBP/Ku p70 corresponds to the mutagen-sensitive mus309 gene and is involved in P-element excision in vivo. Genes and Development, 10, 921-933. doi:10.1101/gad.10.8.921

[24] Weinstein, A. (1936) The theory of multiple-strand crossing over. Genetics, 21, 155-199.

[25] Stevens, W.L. (1936) The analysis of interference. Journal of Genetics, 32, 51-64. doi:10.1007/BF02982501

[26] Grell, R.F. and Chandley, A.C. (1965) Evidence bearing on the coincidence of exchange and DNA replication in the oocyte of Drosophila melanogaster. Proceedings of the National Academy of Sciences USA, 53, 1340-1346. doi:10.1073/pnas.53.6.1340

[27] Grell, R.F. (1972) Recombination and DNA replication in the Drosophila melanogaster oocyte. Genetics, 73, 87108.

[28] Portin, P. and Suormala, T. (1973) Timing of meiotic crossing-over in Drosophila melanogaster. Hereditas, 75, 267-272. doi:10.1111/j.1601-5223.1973.tb01168.x

[29] Mehrotra, S. and McKim, K.S. (2006) Temporal analysis of meiotic DNA double-strand break formation and repair in Drosophila females. Public Library of Sciences Genetics, 2, 1883-1897.

[30] Joyce, E.F. and McKim, K.S. (2009) Drosophila PCH2 is required for a pachytene checkpoint that monitors double-strand-break-independent events leading to meiotic crossover formation. Genetics, 181, 39-51. doi:10.1534/genetics.108.093112

[31] Baker, B.S. and Hall, J.C. (1976) Meiotic mutants: Genetic control of meiotic recombination and chromosome segregation. In: Ashburner, M. and Novitski, E., Eds., The Genetics and Biology of Drosophila, Vol. 1a, Academic Press, London, 351-434.

[32] Sandler, L., Lindsley, D.L., Nicoletti, B. and Trippa, G. (1968) Mutants affecting meiosis in natural populations of Drosophila melanogaster. Genetics, 60, 525-558.

[33] Baker, B.S. and Carpenter, A.T.C. (1972) Genetic analysis of sex chromosomal meiotic mutants in Drosophila melanogaster. Genetics, 71, 255-286.

[34] Fujitani, Y., Mori, S. and Kobayashi, I. (2002) A reaction-diffusion model for interference in meiotic crossing over. Genetics, 161, 365-372. 